\title{
Demonstration of the effectiveness of zinc in diarrhoea of children living in Switzerland
}

\author{
Pierre Alex Crisinel • Marie-Elise Verga • \\ Konan Sallert Alexis Kouame • Anne Pittet • \\ Céline Gasser Rey-Bellet • Olivier Fontaine • \\ Ermindo Roberto Di Paolo • Mario Gehri
}

Received: 14 November 2014 /Revised: 17 February 2015 / Accepted: 24 February 2015 /Published online: 7 March 2015

(C) Springer-Verlag Berlin Heidelberg 2015

\begin{abstract}
We designed a double-blinded randomized clinical trial of zinc ( 10 or $20 \mathrm{mg}$ of zinc sulphate for $2-5$ month-old or 6-59 month-old children, respectively, during 10 days) vs. placebo in otherwise healthy children aged 2 months to 5 years who presented with acute diarrhoea (i.e. $\geq 3$ stools/day for less than $72 \mathrm{~h}$ ). Eighty-seven patients (median age 14 months; range 3.1-58.3) were analysed in an intention-to-treat approach. Forty-two patients took zinc and 45 placebo. There was no difference in the duration nor in the frequency of diarrhoea, but only $5 \%$ of the zinc group still had diarrhoea at $120 \mathrm{~h}$ of treatment compared to $20 \%$ in the placebo group
\end{abstract}

Communicated by David Nadal

P. A. Crisinel $(\bowtie) \cdot$ M.-E. Verga $\cdot$ K. S. A. Kouame $\cdot$ A. Pittet

C. G. Rey-Bellet • E. R. Di Paolo • M. Gehri

Medico-Surgical Paediatric Department, Lausanne University

Hospital, Lausanne, Switzerland

e-mail: pierre-alex.crisinel@chuv.ch

M.-E. Verga

e-mail: marie-elise.dufey@chuv.ch

K. S. A. Kouame

e-mail: alexdesallert@yahoo.fr

A. Pittet

e-mail: pittet.anne@chuv.ch

C. G. Rey-Bellet

e-mail: celine.rey-bellet@chuv.ch

E. R. Di Paolo

e-mail: ermindo.di-paolo@chuv.ch

M. Gehri

e-mail: mario.gehri@chuv.ch

O. Fontaine

Child and Adolescent Health and Development, World Health

Organization, Geneva, Switzerland

e-mail: olivier.fontaine1952@gmail.com
$(P=0.05)$. Thirty-one patients (13 zinc and 18 placebo) were available for per-protocol analyses. The median (IQR) duration of diarrhoea in zinc-treated patients was $47.5 \mathrm{~h}(18.3-72)$ and differed significantly from the placebo group (median 76.3; IQR 52.8-137) $(P=0.03)$. The frequency of diarrhoea was also lower in the zinc group $(P=0.02)$.

Conclusion: zinc treatment decreases the frequency and severity of diarrhoea in children aged 2 months to 5 years living in Switzerland. However, the intention-to-treat analysis reveals compliance issues that question the proper duration of treatment and the choice of optimal pharmaceutical formulation.

\footnotetext{
What is known

- The effectiveness of zinc in childhood diarrhoea has been demonstrated in developing countries. It helps to decrease the duration and severity of diarrhoea. There is currently no sufficient data to justify its use in developed countries, where there is, theoretically, no zinc deficiency.

What is new

- We demonstrated the effectiveness of zinc in diarrhoea of children living in a developed country. This confirms the result of two studies (Passariello 2011, and Dalgic 2011) that also reported the positive impact of zinc in diarrhoea of children living in Italy and in Turkey. However, our population is wider in terms of age (2-60 months compared to 3-36 months for Passariello's study and 1-28 months for Dalgic's study) and is not limited to a specific aetiology or to a certain degree of severity of the diarrhoea. Furthermore, it's the first study that uses a placebo for the control group. The main limitation of our study is the differences in the intention-to-treat and the per-protocol analyses that reveal big compliance problems. These could be dealt by changing the dosage form of the zinc formula and/or by diminishing the treatment duration.
}

Keywords Zinc $\cdot$ Diarrhoea $\cdot$ Developed country $\cdot$ Children · Randomized clinical trial 


$\begin{array}{ll}\text { Abbreviations } \\ \text { IQR } & \text { Interquartile range } \\ \text { ORS } & \text { Oral rehydration solution } \\ \text { UNICEF } & \text { United Nations International Children's } \\ & \begin{array}{l}\text { Emergency Fund } \\ \text { WHO }\end{array} \\ \text { World Health Organization }\end{array}$

\section{Introduction}

Diarrhoea remains the second leading cause of death due to infection in children under 5 years of age [9]. Since 2004, the World Health Organization (WHO) and the United Nations International Children's Emergency Fund (UNICEF) have recommended zinc for the management of diarrhoea in children. Its effectiveness on the duration and severity of diarrhoea has been demonstrated in studies conducted in the developing world [8], although the exact mechanisms of action of zinc in diarrhoea have not been established. However, several known zinc-associated effects could explain its impact: (1) zinc stimulates the immune system [3]; (2) zinc enhances regeneration of the intestinal mucosa and the level of enzymes present at the intestinal surface [3]; and (3) the antisecretory action of zinc in the gastrointestinal tract has been demonstrated in an animal model [7]. The latter is relevant to developed countries where, in principle, children show no zinc deficiency.

Currently, there are no recommendations regarding the use of zinc in developed countries. A Turkish study published in 2006 did not show a benefit of zinc in a population of children aged 6 to 60 months [5], yet two other studies have demonstrated the effectiveness of zinc in specific populations $[6,10]$. To determine whether the use of zinc might be beneficial in the Swiss paediatric population, a randomized clinical trial (zinc vs. placebo) was conducted with patients aged 2 months to 5 years with diarrhoea of any severity or aetiology.

\section{Materials and methods}

Design, setting and patients

A double-blinded randomized clinical trial was conducted in a tertiary paediatric hospital in Lausanne (Hôpital de l'Enfance, Lausanne University Hospital) between October 2010 and October 2013. Children aged 2 months to 5 years who presented to the emergency department with acute diarrhoea (i.e. 3 or more stools per day for less than $72 \mathrm{~h}$ ) were selected for participation in this study. Exclusion criteria were children of non-French speaking parents, severe malnutrition (weight-forheight was -3 standard deviations from the median specified in the WHO Child Growth Standards or oedema of both feet [14]), ongoing zinc treatment, an overwhelming chronic medical condition, hypersensitivity to a component of the zinc or placebo pills and phenylketonuria. Note that both the zinc and placebo pills contained aspartame. Parents or legal guardians provided written informed consent. Past medical history, history of present illness and physical findings were recorded in a standard case report form at the time of recruitment. Dehydration was classified according to the following WHO criteria [15]: A, no sign of dehydration; B, moderate dehydration (two of the following signs: restlessness or irritability, sunken eyes, drinking eagerly or thirsty, slow skin fold retraction); $\mathrm{C}$, severe dehydration (two of the following signs: lethargy or unconsciousness, sunken eyes, inability to drink or drinking poorly, very slow skin fold retraction). This study was approved by the institutional ethics committee and was conducted in accordance with the requirements stated in the Declaration of Helsinki, Good Clinical Practice standards and Swiss regulations.

\section{Intervention}

Zinc and placebo were presented at the same dosage and in the same packaging as dispersible tablets of 10 or $20 \mathrm{mg}$ zinc sulphate or aspartame (Nutriset SAS, France). The administered dose was $10 \mathrm{mg}$ once a day (QD) in children $<6$ months and $20 \mathrm{mg}$ QD for children $\geq 6$ months. Both age groups were treated for 10 days [15]. If the child vomited within 1 hour after administration of a dose, the parents were instructed to repeat the dose once more. Packets of oral rehydration solution (ORS) were provided by the WHO (WHO KBI solution), and 3 of these were also given to each child (equivalent to 3 1). The medical management of acute diarrhoea was conducted according to WHO recommendations [15].

\section{Outcomes}

The main outcome measures were reductions in the duration and the severity (frequency) of diarrhoea. The impact of zinc on the frequency of diarrhoea (i.e. the number of diarrhoeal stools) was measured between day 2 (to disregard spontaneous resolution of diarrhoea on the first day of treatment) and day 4 of treatment (because most diarrhoea will be resolved on the 5th day). The end of diarrhoea was defined as the time of the last loose stool before two consecutive normal stools or the absence of stools for $24 \mathrm{~h}$. A secondary outcome measure was the occurrence of side effects. Patient tracking information (i.e. treatment compliance, evolution of diarrhoea and treatment side effects) were reported in a questionnaire filled out by the parents or guardians each day for 14 days. 
Sample size calculation and randomization

The estimated proportion of patients with spontaneous resolution of diarrhoea at $72 \mathrm{~h}$ was $43 \%$ based on a sample of patients treated in our institution. We estimated that 200 children (100 in each group) would be adequate to detect a $20 \%$ difference in the proportion of diarrhoea-free patients with $80 \%$ power and $95 \%$ confidence. We asked the WHO to perform a block randomization, with a block size of 8 , in a double-blinded manner. A separate randomization was performed for the 2- to 5-month-old and the 6- to 59-month-old children. Our institutional pharmacy assigned a study number to each package of placebo or zinc (plus three packets of ORS) according to the group to which each patient was randomly assigned.

\section{Statistical analyses}

Fisher's exact test for categorical data and Kruskal-Wallis or Student's $t$ test for continuous data were used to compare patient characteristics and to analyse zinc or placebo effects on the studied outcomes. The proportion of patients still having diarrhoea at each time point of placebo and zinc treatment were plotted on Kaplan-Meier curves and analysed with the log-rank test. Patients lost to follow-up were censored from the analyses. Intention-to-treat (for all randomized patients not

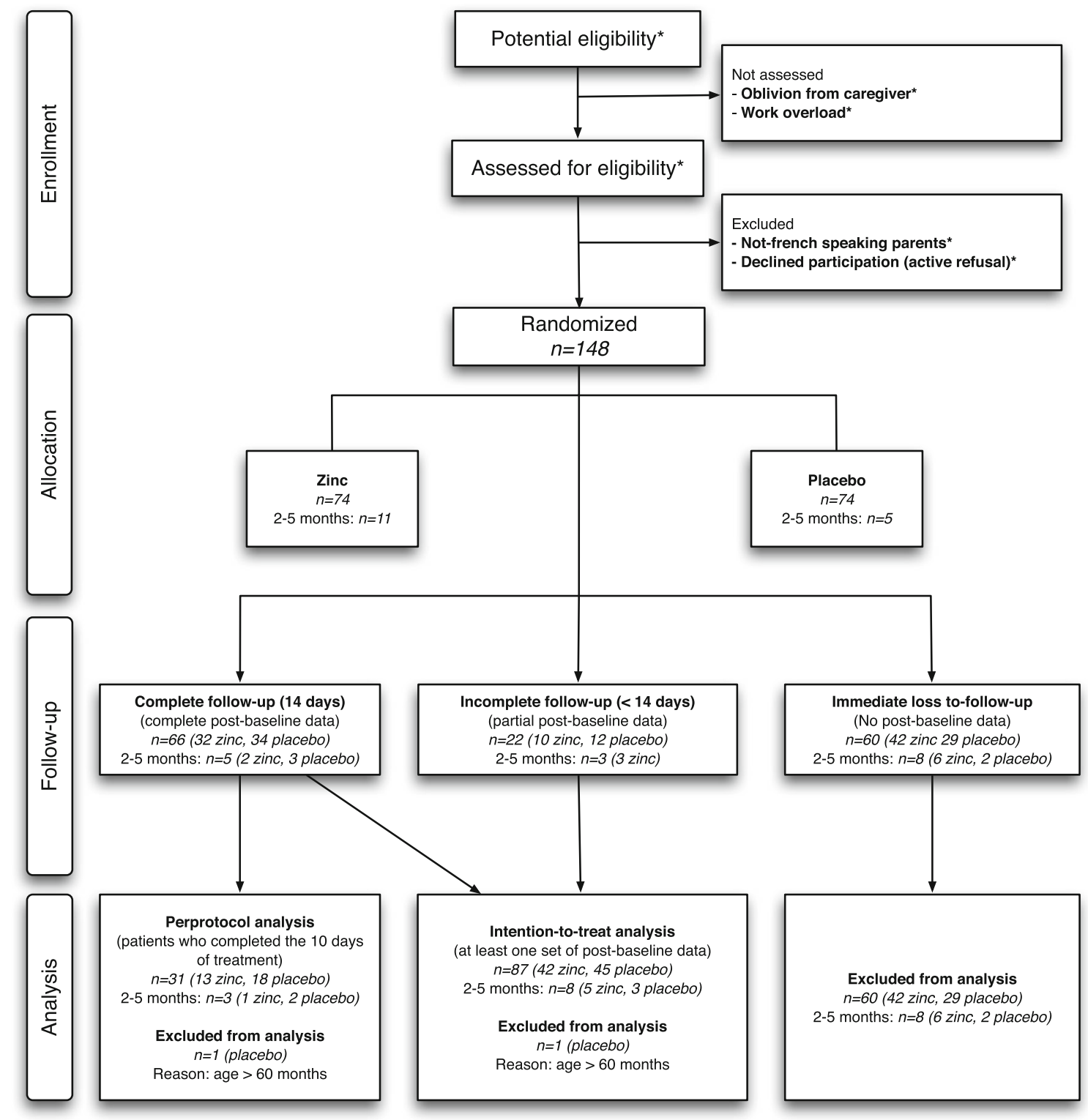

Fig. 1 Flowchart of subject selection. Asterisks indicate that the exact number of excluded patients due to non-assessment, language issues, or active refusal from parents is not known. We estimated that these exclusions represented $40-50 \%$ of the potentially eligible population 
lost to follow-up) and per-protocol (for all patients completing the trial according to the protocol) analyses were performed. All tests were two-tailed, and a $P$ value $\leq 0.05$ was considered statistically significant. All analyses were performed using the Stata version 11.2 (StataCorp, Texas, USA) software package for Mac (Apple Inc., California, USA).

\section{Results}

Study population statistics

A total of 148 patients were recruited for this study; 74 were in the zinc group and 74 were in the placebo group (Fig. 1). One patient was secondarily excluded for being older than 5 years of age. Sixty patients were lost to follow-up without any available post-baseline data. Of the remaining 87 patients (42 zinc and 45 placebo), 65 completed their follow-up (14 days) and 31 were available for per-protocol analysis. The median age of the remaining 87 patients was 14 months (range 3.1-58.3) and $34(39 \%)$ were female (Table 1$)$. Only 8 patients were aged less than 6 months ( 5 in the zinc group and 3 in the placebo group). Of these patients, 4 (1 zinc and 3 placebo) were available for per-protocol analyses. Caucasian was the largest ethnic group (32/69, $46 \%)$. The median (IQR) duration of diarrhoea prior to consultation was $27 \mathrm{~h}(12-42.5)$. The majority of patients $(63 / 87,72 \%)$ had WHO stage A dehydration, and 19 patients (22\%) were hospitalized. Overall, good health was observed for all of the patients, and no clinical (blood and/or mucous) or diagnostic evidence for a microbial aetiology were found. Differences in the clinical and demographic

Table 1 Clinical and demographic characteristics of the study population

\begin{tabular}{|c|c|c|c|c|}
\hline Characteristics & $\begin{array}{l}\text { All subjects } \\
(n=87)\end{array}$ & $\begin{array}{l}\text { Zinc } \\
(n=42)\end{array}$ & $\begin{array}{l}\text { Placebo } \\
(n=45)\end{array}$ & $\begin{array}{l}P \\
\text { value }\end{array}$ \\
\hline Female gender, $n(\%)$ & $34(39)$ & $18(43)$ & $16(36)$ & 0.5 \\
\hline $\begin{array}{l}\text { Caucasian } \\
\quad \text { race/ethnicity, } n(\%)\end{array}$ & $32 / 69^{\mathrm{a}}(46)$ & $\begin{array}{r}16 / 33^{\mathrm{a}} \\
(49)\end{array}$ & $16 / 36^{\mathrm{a}}(44)$ & 0.7 \\
\hline $\begin{array}{l}\text { Median age at } \\
\text { enrollment } \\
\text { (months), (range) }\end{array}$ & $14(3.1-58.3)$ & $\begin{array}{l}13.5(3.1- \\
58.3)\end{array}$ & $\begin{array}{c}14.3(3.6- \\
49.2)\end{array}$ & 0.8 \\
\hline $\begin{array}{l}\text { WHO stage A } \\
\text { dehydration } \\
(<5 \%), n(\%)\end{array}$ & $63(72)$ & $29(69)$ & $34(76)$ & 0.5 \\
\hline $\begin{array}{l}\text { Hospitalization (days), } \\
\quad n(\%)\end{array}$ & $19(22)$ & $9(21)$ & $10(22)$ & 0.9 \\
\hline $\begin{array}{l}\text { Partial breastfeeding, } \\
n(\%)\end{array}$ & $8 / 73^{\mathrm{a}}(11)$ & $4 / 36^{\mathrm{a}}(11)$ & 4/44 (9) & 1 \\
\hline $\begin{array}{c}\text { Median (IQR) duration } \\
\text { of diarrhoea prior to } \\
\text { consultation (hours) }\end{array}$ & $27(12-42.5)$ & $\begin{array}{c}28.4(12- \\
41.1)\end{array}$ & $\begin{array}{l}26.5 \\
\quad(13.5- \\
45)\end{array}$ & 0.8 \\
\hline
\end{tabular}

${ }^{\mathrm{a}}$ The number of patients with available data is specified if it is less than the total number of patients characteristics between the zinc- and placebo-treated patients were not significant (Table 1). Moreover, an evaluation of the same characteristics between the 60 patients lost to follow-up and the remaining 87 patients available for outcome analysis did not reveal any significant differences (data not shown).

Intention-to-treat analysis

The median (IQR) duration of diarrhoea in the zinc-treated children was 65 h (27.8-93.2), and it did not significantly differ from that of the placebo group (median 68; IQR 25.5101.2) (Table 2 and Fig. 2). At 72 and $120 \mathrm{~h}$ post-treatment, 79 and 76 patients were assessed for persistent diarrhoea, respectively. At the $72 \mathrm{~h}$ timepoint, 36/79 (46\%) patients still had diarrhoea, and there was no significant difference between the zinc and placebo groups. At the $120 \mathrm{~h}$ timepoint, 2 (5\%) patients and $8(21 \%)$ patients from the zinc and placebo groups still had diarrhoea, respectively $(P=0.05)$. However, there was no significant difference in the frequency of diarrhoea between these groups between days 2 and 4 of treatment.

Per-protocol analysis

Analysis of the Kaplan-Meier curve data (Fig. 3) revealed that the median (IQR) duration of diarrhoea was significantly shorter in the zinc-treated group (47.5 [18.3-72] hours) compared with the placebo-treated group (76.3 [52.8-137] hours). At $72 \mathrm{~h}$ post-treatment, 4 (31\%) zinc-treated patients had persistent diarrhoea compared with $12(67 \%)$ placebotreated patients $(P=0.05)$. At $120 \mathrm{~h}$ post-treatment, the difference in the incidence of persistent diarrhoea was not significant (Table 3). The median (IQR) number of diarrhoeal stools between day 2 and day 4 of treatment was also less in the zinc

Table 2 Duration and frequency of diarrhoea in response to treatment, an intention-to-treat analysis

\begin{tabular}{|c|c|c|c|c|}
\hline Characteristic & $\begin{array}{l}\text { All } \\
\text { subjects }\end{array}$ & Zinc & Placebo & $\begin{array}{l}P \\
\text { value }\end{array}$ \\
\hline $\begin{array}{l}\text { Persistence of diarrhoea at } 72 \mathrm{~h} \text {, } \\
n / \text { total }(\%)\end{array}$ & $\begin{array}{r}36 / 79 \\
\quad(46)\end{array}$ & $\begin{array}{r}17 / 39 \\
(44)\end{array}$ & $\begin{array}{r}19 / 40 \\
(48)\end{array}$ & 0.5 \\
\hline $\begin{array}{l}\text { Persistence of diarrhoea at } 120 \mathrm{~h} \text {, } \\
n / \text { total }(\%)\end{array}$ & $\begin{array}{r}10 / 76 \\
(13)\end{array}$ & $2 / 37(5)$ & $\begin{array}{l}8 / 39 \\
(21)\end{array}$ & $0.05^{\mathrm{a}}$ \\
\hline $\begin{array}{l}\text { Median (IQR) duration of } \\
\text { diarrhoea (hours) } \\
(27.8-93.2) \\
(25.5-101.2)\end{array}$ & $\begin{array}{l}67(27- \\
94) \\
68 \\
0.5\end{array}$ & 65 & & \\
\hline $\begin{array}{l}\text { Median (IQR) number of } \\
\text { diarrhoeal stools between days } 2 \\
\text { and } 4 \text { of treatment; number of } \\
\text { patients with available data }\end{array}$ & $\begin{array}{c}7(3-9) ; \\
65\end{array}$ & $\begin{array}{l}5.5 \\
(2.5- \\
9.5) \\
32\end{array}$ & $\begin{array}{c}8(3-9) \\
33\end{array}$ & 0.7 \\
\hline
\end{tabular}

${ }^{\text {a }}$ Statistically significant 


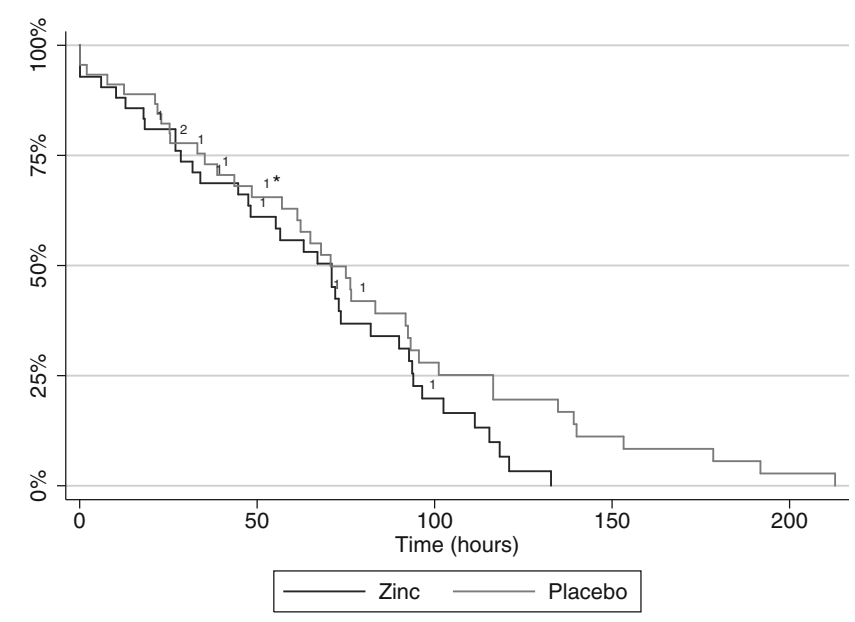

Fig. 2 Persistence of diarrhoea in response to zinc treatment, an intention-to-treat analysis. Kaplan-Meier curves present the percentage of patients that continued to experience diarrhoea with respect to the duration of zinc and placebo treatments. Asterisks indicate the numbers referring to patients that were censored due to loss to follow-up. Log-rank test $(n=87): P=0.08$

group (3 [1-8]) compared to the placebo group (9 [7-9]) $(P=$ $0.02)$.

Side effects

Vomiting that presented after the start of placebo or zinc treatment was reported for 56/87 (64\%) patients. The proportion of vomiting patients in the zinc vs. placebo groups $(30 / 42$, $71 \%$ vs. $26 / 45,58 \%$, respectively) was not significant. The median (IQR) duration of vomiting between the zinc-treated and placebo-treated patients (2 [1-3] days vs. 2.5 [1-5] days, respectively) was also not significant. Per-protocol analyses revealed similar results (data not shown). The proportion of reported difficulties in treatment administration between the

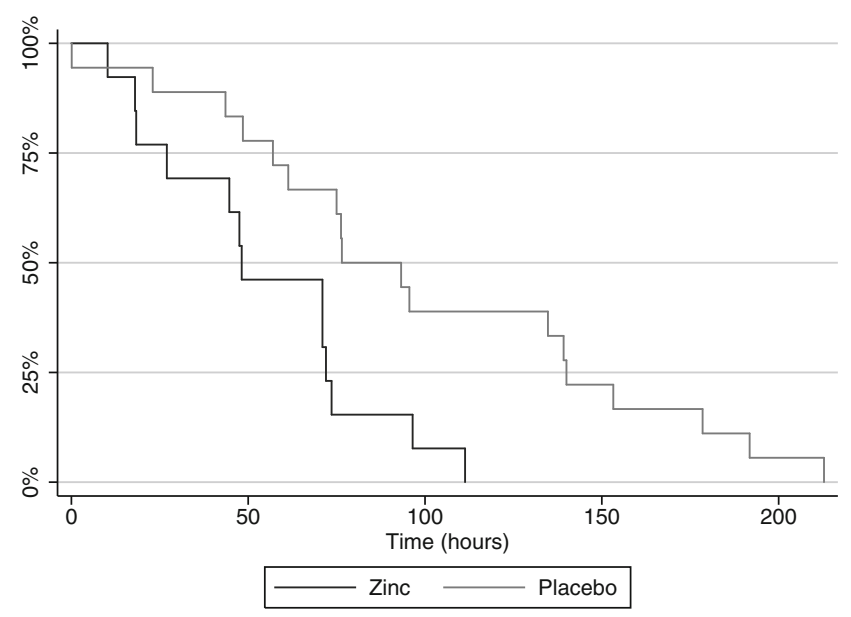

Fig. 3 Persistence of diarrhoea in response to zinc treatment, a perprotocol analysis. Kaplan-Meier curves represent the percentage of patients still having diarrhoea with respect to the duration of zinc and placebo treatments. Log-rank test $(n=31): P=0.009$
Table 3 Duration and frequency of diarrhoea in response to treatment, a per-protocol analysis

\begin{tabular}{|c|c|c|c|c|}
\hline Characteristic & $\begin{array}{l}\text { All } \\
\text { subjects }\end{array}$ & Zinc & Placebo & $\begin{array}{l}P \\
\text { value }\end{array}$ \\
\hline $\begin{array}{l}\text { Persistence of diarrhoea at } 72 \mathrm{~h}, \\
n / \text { total }(\%)\end{array}$ & $\begin{array}{r}16 / 31 \\
\quad(52)\end{array}$ & $\begin{array}{l}4 / 13 \\
(31)\end{array}$ & $\begin{array}{r}12 / 18 \\
(67)\end{array}$ & $0.05^{\mathrm{a}}$ \\
\hline $\begin{array}{l}\text { Persistence of diarrhoea at } 120 \mathrm{~h} \text {, } \\
n / \text { total }(\%)\end{array}$ & $\begin{array}{l}8 / 31 \\
(26)\end{array}$ & $1 / 13(8)$ & $\begin{array}{l}7 / 18 \\
(39)\end{array}$ & 0.06 \\
\hline $\begin{array}{l}\text { Median (IQR) duration of } \\
\text { diarrhoea (hours) } \\
(43.6-95.6) \\
(18.3-72) \\
(52.8-137)\end{array}$ & $\begin{array}{l}71 \\
47.5 \\
76.3 \\
\\
0.03^{\mathrm{a}}\end{array}$ & & & \\
\hline $\begin{array}{l}\text { Median (IQR) number of diarrhoeal } \\
\text { stools between days } 2 \text { and } 4 \text { of } \\
\text { treatment; number of patients } \\
\text { with available data }\end{array}$ & $\begin{array}{c}8(3-9) \\
29\end{array}$ & $\begin{array}{c}3(1-8) \\
11\end{array}$ & $\begin{array}{c}9(7-9) \\
18\end{array}$ & $0.02^{\mathrm{a}}$ \\
\hline
\end{tabular}

${ }^{\text {a }}$ Statistically significant

zinc-treated (19/42, $45 \%$ ) and placebo-treated (20/45, $44 \%)$ patients also did not significantly differ. Only 5 patients $(2$ zinc, 3 placebo) required readministration of treatment due to vomiting. The parents did not report any other notable side effects.

\section{Discussion}

The present study demonstrates the effectiveness of zinc treatment in a paediatric population of a high-income country. The results of the per-protocol analysis show a reduction of more than $24 \mathrm{~h}$ in the duration of diarrhoea and a diminution in the frequency of diarrhoea. These results are statistically and clinically significant and demonstrate that zinc should be considered for the management of diarrhoea in developed countries. Thus, our study challenges the conclusions of a recent Cochrane review regarding the use of zinc in our setting [8]. However, the intention-to-treat analysis reveals compliance issues that question the proper duration of treatment and the choice of optimal pharmaceutical formulation.

Compared with previously published studies, the present study has several strengths. One, patients were enrolled without regard for the severity or the aetiology of the diarrhoea manifested. To our knowledge, the present study is also the first to use a placebo control group in a developed country. In a previous study, a positive effect of zinc on diarrhoea was demonstrated in a population of Italian children aged 3 to 36 months who were treated in private paediatric clinics for acute diarrhoea (for a duration less than $24 \mathrm{~h}$ ) with mild to moderate dehydration [10]. The investigators compared 59 patients who were treated with an ORS containing zinc and prebiotics (Super ORS) to 60 patients treated with a standard ORS. They showed that $72.9 \%$ of the patients that received 
Super ORS no longer experienced diarrhoea at $72 \mathrm{~h}$ posttreatment compared with $50 \%$ of the patients that received a standard ORS $(P=0.01)$. They also reported that the mean number of working days missed by the parents of the patients taking Super ORS was less than the number of working days reported missed by the parents of the standard ORS-treated patients $(0.39$ vs. $1.45, P<0.001)$. Another study was conducted in a population of Turkish children aged 1 to 28 months who were hospitalized for rotavirus-induced gastroenteritis (duration $<96 \mathrm{~h}$ ) [6]. The investigators compared 7 groups (60 patients in each group) that each received a different combination of treatments (Saccharomyces boulardii, lactose-free formula and/or zinc) to a control group (standard ORS). They found that the duration of diarrhoea was significantly reduced in the groups that received zinc alone or zinc plus $S$. boulardii, compared to the control group. A significant difference in the duration of hospitalization was also observed. The mean duration of diarrhoea was 3.41 days in the zinc only-treated group compared to 5.35 days in the control group. The results of the present study are in agreement with these two studies. Moreover, the present results demonstrate the effectiveness of zinc in a more clinically and age diverse population. While Passariello's study [10] was restricted to patients in private practice clinics that presented with diarrhoea for less than $24 \mathrm{~h}$, the current study included patients exhibiting a wider range of severity ( $22 \%$ hospitalization) and that presented with diarrhoea up to $72 \mathrm{~h}$ before recruitment. In addition, we did not restrict the inclusion criteria of the present study to a single pathogen as in Dalgic's study [6] where only hospitalized patients were included. Compliance data were also reported in the current study.

There were several limitations associated with the present study. First, there were a large number of patients lost to follow-up despite repeated phone calls at different times and postal correspondence to the parents of these patients. It is hypothesized that many of the parents felt uncomfortable as a result of poor compliance with the treatment regimen. Indeed, the majority of children stopped having diarrhoea after a few days of treatment, and it is speculated that many of the patients did not maintain their treatment after the diarrhoea stopped. In addition, we may not have sufficiently emphasized that we were not going to blame the parents for lack of compliance and it was more important for us to receive all of the tracking information even if the child did not complete the treatment regimen. Consequently, many parents may have deliberately provided no response to phone calls, no response to voicemail, and no response to letters. Secondly, the lack of compliance explains the intention-to-treat results obtained. There were some parents who clearly reported difficulties in the administration of zinc or placebo, and the metallic taste of zinc certainly played a role. However, there was no significant difference between the compliance or administration difficulties for the two groups. The sweetener that was present in the tablets greatly affects the taste of certain foods or liquids. This can lead to problems in the administration of the treatment to infants and may also lead to a premature discontinuation of treatment, especially when the child has begun to feel better. Thirdly, an insufficient number of 2- to 6-month-old patients were recruited to allow firm conclusions to be made regarding this age group. Moreover, we were unable to recruit the expected number of patients based on our calculations. Our goal was to recruit 200 patients in 2 years. However, a higher proportion of parental refusals to participate in the study were unexpectedly obtained. We estimate that this greatly contributed to the estimated loss of $40-50 \%$ of the total eligible patients. Moreover, we could only extend our study for one additional year due to a lack of manpower. The main reasons for parental refusal were lack of time and unwillingness to let their children participate in a clinical drug trial. These reasons are also consistent with the observation that the proportion of patients with persistent diarrhoea at $120 \mathrm{~h}$ was the only significant difference in the intention-to-treat analyses. The absence of significant results in the other outcome analyses is likely due to a lack of statistical power.

For future studies, it may be important to consider a different pharmaceutical formulation to improve compliance, and ultimately, the effectiveness of zinc treatment. Zinc can be efficiently incorporated in ORS, as evidenced by Passariello's study [10]. However, additional data are needed to provide clear evidence of the effectiveness of zinc-fortified ORS [2, $12,13]$, and compliance issues may persist. For example, it may be difficult to administer ORS for more than a few days. Another question to consider is the optimal duration of treatment. In the placebo group, only a minority of patients still had diarrhoea after 5 days of treatment. Therefore, it seems difficult to justify a prolonged treatment for 10 days, especially since we expect there to be fewer secondary benefits in developing countries, such as a reduced incidence of infectious disease in the 23 months following zinc administration [4]. Some data suggest that zinc treatments with a shorter duration can provide a beneficial effect [1], although the positive impact of zinc on appetite could represent an advantage of extending a treatment course [11]. While these issues were not evaluated in the present study, they remain to be examined.

In conclusion, the present study provides new evidence that supports the effectiveness of administering zinc for the treatment of diarrhoea in developed countries. Thus, health authorities should consider including zinc in the treatment of diarrhoea. Furthermore, administration of zinc in a more simplified form could potentially maximize compliance, and hence, the effectiveness of treatment. Additional studies are also needed to prove the effectiveness of zinc when included in ORS and the effectiveness of zinc over a shorter treatment period. 
Acknowledgments We thank the members of the paediatric research platform of Lausanne Childhood Hospital, The Foundation of Lausanne Childhood Hospital, who provided the first author with a research grant. We also thank the World Health Organization for providing ORS and the Nutriset Company for providing zinc and placebo tablets. We thank Béatrice Pelet from the CHUV pharmacy for the randomization and preparation of study packages, and all of the dedicated caretakers, parents, and patients who contributed to this study.

Conflicts of interest The authors declare that they have no conflicts of interest to report.

\section{References}

1. Al-Sonboli N, Gurgel RQ, Shenkin A, Hart CA, Cuevas LE (2003) Zinc supplementation in Brazilian children with acute diarrhoea. Ann Trop Paediatr 23:3-8

2. Bahl R, Bhandari N, Saksena M, Strand T, Kumar GT, Bhan MK, Sommerfelt H (2002) Efficacy of zinc-fortified oral rehydration solution in 6- to 35-month-old children with acute diarrhea. YMPD 141:677-682

3. Bajait C, Thawani V (2011) Role of zinc in pediatric diarrhea. Indian J Pharmacol 43:232-235

4. Bhutta ZA, Black RE, Brown KH, Gardner JM, Gore S, Hidayat A, Khatun F, Martorell R, Ninh NX, Penny ME, Rosado JL, Roy SK, Ruel M, Sazawal S, Shankar A (1999) Prevention of diarrhea and pneumonia by zinc supplementation in children in developing countries: pooled analysis of randomized controlled trials. Zinc Investigators' Collaborative Group. J Pediatr 135:689-697

5. Boran P, Tokuc G, Vagas E, Oktem S, Gokduman M (2006) Impact of zinc supplementation in children with acute diarrhoea in Turkey. Arch Dis Child 91:296-299
6. Dalgic N, Sancar M, Bayraktar B, Pullu M, Hasim O (2011) Probiotic, zinc and lactose-free formula in children with rotavirus diarrhea: are they effective? Pediatr Int 53:677-682

7. Hoque KM, Rajendran VM, Binder HJ (2005) Zinc inhibits cAMPstimulated $\mathrm{Cl}$ secretion via basolateral $\mathrm{K}$-channel blockade in rat ileum. Am J Physiol Gastrointest Liver Physiol 288:G956-G963

8. Lazzerini M, Ronfani L (2013) Oral zinc for treating diarrhoea in children. Cochrane Database Syst Rev John Wiley \& Sons, Ltd 1: CD005436

9. Liu L, Johnson HL, Cousens S, Perin J, Scott S, Lawn JE, Rudan I, Campbell H, Cibulskis R, Li M, Mathers C, Black RE, Child Health Epidemiology Reference Group of WHO and UNICEF (2012) Global, regional, and national causes of child mortality: an updated systematic analysis for 2010 with time trends since 2000. Lancet 379: 2151-2161

10. Passariello A, Terrin G, De Marco G, Cecere G, Ruotolo S, Marino A, Cosenza L, Tardi M, Nocerino R, Berni Canani R (2011) Efficacy of a new hypotonic oral rehydration solution containing zinc and prebiotics in the treatment of childhood acute diarrhea: a randomized controlled trial. J Pediatr 158:288-292, e1

11. Umeta M, West CE, Haidar J, Deurenberg P, Hautvast JG (2000) Zinc supplementation and stunted infants in Ethiopia: a randomised controlled trial. Lancet 355:2021-2026

12. Wadhwa N, Natchu UCM, Sommerfelt H, Strand TA, Kapoor V, Saini S, Kainth US, Bhatnagar S (2011) ORS containing zinc does not reduce duration or stool volume of acute diarrhea in hospitalized children. J Pediatr Gastroenterol Nutr 53:161-167

13. Walker CLF (2011) Is there a real benefit to zinc and prebiotic fortified ORS in children under the age of 3 years? Evid-Based Nurs 14: 113-114

14. World Health Organization (2013) Chapter 7 Severe acute malnutrition. In World Health Organization (ed) Pocket book of Hospital care for children World Health Organization, pp 197-222

15. World Health Organization (2013) Chapter 5 Diarrhoea. In World Health Organization (ed) Pocket book of Hospital care for children World Health Organization, pp 125-147 